\title{
Psychosocial risk factors and mortality: A prospective study with special focus on social support, social participation, and locus of control in Norway
}

Odd Steffen Dalgard, Lise Lund Håheim

\begin{abstract}
Study objective-The objective is to investigate the effect on mortality of psychosocial variables, with special focus on social support, social participation, and locus of control.

Design-The study is designed as a prospective study with a 17 year follow up period, using univariate and multivariate proportional hazards regression analysis to estimate the predictive power of psychosocial variables, when controlling for sociodemographic and biological factors. Setting-The study is based on a population sample randomly drawn from different neighbourhoods of Oslo in 1975/76, for the purpose of surveying health, in particular mental health, in relation to various social and psychosocial variables. The initial data were gathered by structured interviewing, whereas the data about mortality and cause of death, was gathered from the Central Bureau of Statistics.
\end{abstract}

Participants-The initial sample included 1010 persons above the age of 18 years, with no upper age limit. The follow up with respect to mortality covered the whole sample, with the exception of a very few who had left the country.

Main results-When controlling for sociodemographic and biological factors, low social participation, and to a lesser extent, few close relationships and external locus of control, were associated with increased mortality.

Conclusion-The effect of social participation and locus of control may indicate that life style, and individual psychological resources, are at least as important for survival as support from others in stressful life situations.

(F Epidemiol Community Health 1998;52:476-481)

National Institute of Public Health, Section SAFH, PO 4404, 0403

Oslo, Norway

O S Dalgard

Life Insurance

Institute of Medical

Statistics, Ullevål

Hospital, Oslo, Norway

L Lund Håheim

Correspondence to:

Dr Dalgard.

Accepted for publication

16 September 1997 particular, increases when social support is weak and social participation is low. This holds even when controlling for well known physiological risk factors, like smoking, drinking, unsound eating habits, and lack of physical exercise, as well as increased serum cholesterol and increased blood pressure. ${ }^{1-6}$ With respect to CHD there are also studies showing that the incidence of non-fatal CHD, as well as the outcome when CHD has occurred, is unfavourably influenced by lack of social support and lack of social participation. ${ }^{7-9}$

The explanation of why these psychosocial variables exert a negative influence on somatic health, is, however, not clear. One possibility is, as suggested by Syme, that the effect of lacking social support, and not being socially involved, goes through the lack of control over own life situation. ${ }^{10}$ Being without support from other people, and/or not being member of any organisations or groups, may reduce the chances of successful coping in difficult life situations. This, again, is known to increase stress, ${ }^{11-14}$ which may affect somatic health in various ways, for instance through the endocrine or immune system, or both. The sympathetic-adrenal-medullary system and the catacholamines are thought to be the most common pathway betweem stress and cardiovascular disorder, whereas the pituitaryadrenal-corticol system and the glucocorticoids seem to be the most common pathway between stress and infectious disorders, and probably tumour development, through immunosupression. ${ }^{15}$ That lack of control has a negative effect on somatic health, is also in accordance with Antonowsky, who suggests that reduced "sense of coherence", in which lack of ability to control your own life is a central element, is detrimental to health. ${ }^{16}$

The negative effects of lacking control over your own life situation is also shown in studies about psychosocial work environment and health. In job situations with high demands and low control (high strain jobs) an increase in stress as well as an increase in the incidence of cardiovascular and other diseases is found. ${ }^{17}$ Even here social support seems to play a part, by increasing control, and diminishing stress. ${ }^{18}$

However, mechanisms other than reduced coping and increased stress, are suggested as explanations for the negative effect of lacking social support and participation on somatic health. Some explanations are related to life style, others to personality factors. 
With respect to life style, it is shown that people who are socially relatively isolated and passive, are more inclined to have an unhealthy life style with respect to smoking, alcohol consumption, eating habits, and physical activity than other people. ${ }^{19}$ Even if the effects of these factors are controlled for in most studies, there is still the possibility that socially isolated and passive people develop a more unhealthy life style than others, in the period between observation and death.

With respect to personality factors that may act as explanatory variables, locus of control is of considerable interest. Even if there has not been much research in this field, there are studies indicating that locus of control, as measured by Rotter's scale, affect coronary prone behaviour as well as cardiovascular reactions, in terms of external locus of control being a negative factor. ${ }^{20} 21$

To clarify those factors more important for somatic health - the psychosocial or the personality factors - more longitudinal studies are needed, where both sets of factors are included. This study aims to do this, including locus of control as well as social support, social participation and a number of other psychosocial factors possibly related to health and survival.

\section{Methods}

SUBJECTS

The sample consists of 1010 randomly selected people above the age of 20 years from different neighbourhoods in Oslo, being subject to an extensive structured interview between 1974 and 1976 . The sample was fairly representative of the adult population of Oslo at the actual point in time. The aim of this initial survey was to study the relation between social environment and health, with special emphasis upon mental health and psychosocial variables. The main result was that mental health problems were most frequent in a new and poorly integrated neighbourhood in the outskirts of Oslo, where the combination of various social stressors and poor social support seemed to play an important part in quality of life and mental health. ${ }^{22}$ In a follow up study 10 years later, the combination of poor social network and recent negative life events, in combination with external locus of control, predicted depression, but not anxiety. ${ }^{23}$

With respect to mortality the study population was followed up on average 17 years later, and data about cause of death were gathered by the Central Bureau of Statistics.

VARIABLES

The potential predictors of mortality consist of three groups: sociodemographic variables, biological variables, and psychosocial variables. Among the sociodemographic variables there are data on marital status, education, occupation, income and migration, as well as age and sex. Among the biological variables there are anamnestic data about health, including a check list for the more serious diagnoses, with special focus upon cardiovascular disorder (heart infarction, hypertension, and angina pectoris). Among biological risk factors there are data on smoking, physical exercise, and self rated health status. All information was based on self reporting, and no attempts were made to check the reliability of the reports. Among the psychosocial variables there are data about social network, social participation, mental health, and locus of control. The last variable is based on an abbreviated version of Rotter's locus of control scale, including 12 pairs of questions, which has been used in several Norwegian studies. ${ }^{24}$ Chronbach's alpha in the present sample was 0.59 . Mental health was measured by a 45 item abbreviation of the questionnaire used by Leighton et al in the Stirling County Study. ${ }^{25}$ This gives a general mental health score, as well as scores on various syndromes. The social network is described in terms of perceived quality of relationships, frequency of contacts, number of close relationships, whereas social participation is described in terms of an index based on number of memberships in organised groups and associations, frequency of attendance of meetings as well as the respondents assessment of the importance of the actual groups or associations, and own possibility to influence decisions in these social settings.

\section{DATA ANALYSES}

Rates of mortality are presented by number of cases by number of person years of persons under risk. Group comparisons were done by rate ratios presented with $95 \%$ confidence intervals. The rates of mortality are presented for men, women, and both, and the rate ratio of men to women. The diagnosis used were according to the ICD-8 codes (and corrected when ICD-9 codes were used): cancer 140209, all cardiovascular diseases (CVD) 390458,795 . The remaining causes of mortality are presented as "other causes of mortality".

The assumed risk factors of mortality are presented by their mean or percentage and standard deviation (SD) grouped as sociodemographic, biological, and psychosocial variables for men, women, and both. Missing values were substituted with mean values to get complete sets of data for analytical purposes. This procedure was done for 7 of 23 variables and at most for 81 of 1003 persons for one variable. To examine the effect of replacing missing values with mean values a comparision of the Cox regression coefficients and mean values for the major risk factors with and without substitution was made. The changes were very small, implying that the substitution did not have any influence on the results of the study.

The proportional hazards regression analysis (Cox) was used to examine risk factors effect on mortality during the follow up period. To examine the proportionality of the model the effect of stratification on age was examined. When age was dichotomised in age $<45$ and age $\geqslant 45$ the diagram showed acceptable proportionality. The age adjusted analyses of single risk factors are presented by hazard ratio and $95 \%$ confidence intervals on mortality by one unit change of the risk factor. The multivariate models were based on those 
Table 1 Rate of mortality (age adjusted by direct method) of cardiovascular disorders (CVD), cancer, other causes, and total mortality for men and women and the rate ratio of men to women

\begin{tabular}{|c|c|c|c|c|c|c|c|}
\hline & \multicolumn{2}{|c|}{ All $(n=1003)$} & \multicolumn{2}{|c|}{ Men $(n=439)$} & \multicolumn{2}{|c|}{ Women $(n=563)$} & \multirow{2}{*}{$\begin{array}{l}\text { Men/ } \\
\text { women } \\
R R \ddagger\end{array}$} \\
\hline & Number* & Ratef & Number* & Ratef & Number* & Ratef & \\
\hline $\mathrm{CVD}^{\star}$ & 114 & 3.10 & 43 & 2.52 & 71 & 3.91 & 0.64 \\
\hline Cancer & 49 & 1.42 & 25 & 1.48 & 24 & 1.54 & 0.96 \\
\hline Other causes & 54 & 1.04 & 28 & 2.36 & 26 & 1.57 & 1.50 \\
\hline Total mortality & 217 & 6.40 & 96 & 6.37 & 121 & 6.67 & 0.96 \\
\hline
\end{tabular}

*Number of cases; trate: number of cases per 1000 person years; $\ddagger R R$ : rate ratio of men/women.

variables that were significant at $\mathrm{p}<0.05$ in the age adjusted analyses.

\section{Results}

Table 1 shows the rate of total mortality and major classes of diseases - that is, all CVD, all cancers, and other causes.

CVD accounted for more than half of a total of 217 deaths. There was no significant sex difference for any cause of death. The rate ratio of men to women of total mortality was 0.96 and non-significant.

Table 2 shows the distribution of sociodemographic, biological, and psychosocial risk factors.

The women were found to be older on average. More women than men received social security. The men were from families with a higher household income. More men than women were married.

More women had suffered previous somatic illness and had been hospitalised in the last year. Of cardiovascular related diseases women reported to suffer more often from high blood pressure. No difference was recorded in the occurrence of angina. More men than women had suffered a myocardial infarction. More men were daily cigarette smokers. Men were found to be more active in sport and outdoor exercise than women.

\section{KEY POINTS}

- Psychosocial factors are important predictors of mortality, even when controlling for the effect of sociodemographic factors and known biological risk factors.

- Social participation, in terms of taking active part in organised groups and associations, seems to be at least as important as social support as predictor of a long life.

- External locus of control, in terms of a supposedly personality related feeling of powerlessness, predicts mortality.

- Number of close relationships predicts mortality from cardiovascular diseases among men.

Men and women assessed their general health to be equally well. Women showed better relationships with the family, whereas relationship with friends and neighbours, as well as total number of close relationships were similar for men and women. Men scored lowest on the Rotter scale (more men than women had an internal locus of control) and on religious engagement, but scored higher on social participation. There was no large difference recorded for frequency of interpersonal contact. Men scored highest on the index of mental health, meaning that they had less mental health problems. Twice as many women as men reported to be depressed.

Age was adjusted for in the proportional regression analyses (Cox) of risk factors predicting total mortality (table 3 ).

With the exception of age, none of the sociodemographic variables had a significant effect

Table 2 Risk factors presented by mean (SD) or per cent (SD) for men, women, and all

\begin{tabular}{|c|c|c|c|c|c|c|}
\hline \multirow[b]{2}{*}{ Risk factor } & \multicolumn{2}{|l|}{ Men } & \multicolumn{2}{|l|}{ Women } & \multicolumn{2}{|l|}{ All } \\
\hline & Number* & $\begin{array}{l}\text { Mean/per } \\
\text { cent }(S D)\end{array}$ & Number* & $\begin{array}{l}\text { Mean/per } \\
\text { cent }(S D)\end{array}$ & Number* & $\begin{array}{l}\text { Mean/per } \\
\text { cent }(S D)\end{array}$ \\
\hline \multicolumn{7}{|l|}{ Sociodemographic } \\
\hline Age at screening $(y)$ & 439 & $44.7(16.3)$ & 562 & $47.6(17.6)$ & 1002 & $46.3(17.1)$ \\
\hline Household income (1-9) (1=lowest) & 419 & $6.5(2.0)$ & 530 & $6.2(2.3)$ & 950 & $6.3(2.2)$ \\
\hline Social security $(0=$ no, $1=$ yes $)$ & 439 & $2 \%(0.01)$ & 563 & $5 \%(0.01)$ & 1002 & $4 \%(0.01)$ \\
\hline Married $(0=$ no, $1=$ yes $)$ & 439 & $77 \%(0.02)$ & 563 & $63 \%(0.02)$ & 1003 & $69 \%(0.01)$ \\
\hline \multicolumn{7}{|l|}{ Biological } \\
\hline Somatic illness ever $(0-3)(0=$ none $)$ & 439 & $0.8(0.8)$ & 563 & $1.0(1.0)$ & 1003 & $0.9(0.9)$ \\
\hline Hospitalisation last year $(0=$ no, $1=$ yes $)$ & 439 & $5 \%(0.01)$ & 563 & $9 \%(0.01)$ & 1003 & $8 \%(0.01)$ \\
\hline Increased blood pressure $(0=$ no, $1=$ yes $)$ & 439 & $9 \%(0.01)$ & 563 & $12 \%(0.01)$ & 1003 & $10 \%(0.01)$ \\
\hline Angina pectoris $(0=$ no, $1=$ yes $)$ & 439 & $6 \%(0.01)$ & 563 & $6 \%(0.01)$ & 1003 & $6 \%(0.01)$ \\
\hline Myocardial infarction $(0=$ no, $1=$ yes $)$ & 439 & $4 \%(0.01)$ & 563 & $2 \%(0.01)$ & 1003 & $3 \%(0.01)$ \\
\hline Smoking $(0=$ no, $1=$ yes $)$ & 439 & $54 \%(0.02)$ & 563 & $45 \%(0.02)$ & 1003 & $49 \%(0.02)$ \\
\hline Sport $(1-5)(1=$ most active $)$ & 427 & $2.8(1.3)$ & 549 & $3.2(1.3)$ & 977 & $3.0(1.3)$ \\
\hline $\begin{array}{l}\text { Outdoor exercise }(1-4) \\
(1=\text { most frequent })\end{array}$ & 437 & $1.7(0.9)$ & 559 & $1.9(1.1)$ & 997 & $1.8(1.0)$ \\
\hline \multicolumn{7}{|l|}{ Psychosocial } \\
\hline $\begin{array}{l}\text { Own assessement of health (1-4) } \\
\text { (1=best) }\end{array}$ & 433 & $1.3(0.5)$ & 557 & $1.3(0.6)$ & 991 & $1.3(0.6)$ \\
\hline Relationship family $(0-5)(0=$ best $)$ & 439 & $2.8(1.4)$ & 563 & $3.2(1.4)$ & 1003 & $3.0(1.4)$ \\
\hline Relationship friends $(1-3)(1=\mathrm{best})$ & 439 & $2.2(0.9)$ & 563 & $2.1(0.9)$ & 1003 & $2.2(0.9)$ \\
\hline Relationship neighbours (1-3) (1=best) & 433 & $2.0(0.7)$ & 555 & $1.9(0.8)$ & 989 & $2.0(0.8)$ \\
\hline Close relationships (1-9) & 428 & $4.0(2.7)$ & 549 & $4.2(2.7)$ & 978 & $4.1(2.7)$ \\
\hline Rotter's scale $(0-12)$ (low=internal) & 409 & $4.8(2.3)$ & 513 & $6.0(2.3)$ & 922 & $5.5(2.4)$ \\
\hline Religious engagement $(1-3)(1=$ low $)$ & 435 & $1.1(0.4)$ & 558 & $1.4(0.6)$ & 994 & $1.3(0.6)$ \\
\hline Social participation $(1-3)(1=$ low $)$ & 420 & $2.4(0.8)$ & 547 & $2.1(0.04)$ & 983 & $2.2(0.9)$ \\
\hline Frequency of interpersonal contact $(0-3)$ & 438 & $2.1(0.7)$ & 558 & $2.1(0.1)$ & 997 & $2.2(0.7)$ \\
\hline Mental health $(1-4)(1=$ worst $)$ & 439 & $2.8(1.2)$ & 563 & $2.5(1.2)$ & 1003 & $2.7(1.2)$ \\
\hline Depression $(0=$ no, $1=$ yes $)$ & 439 & $24 \%(0.02)$ & 563 & $45 \%(0.02)$ & 1003 & $36 \%(0.02)$ \\
\hline
\end{tabular}

^Number of persons who replied. 
Table 3 Age adjusted proportional hazards regression analysis of risk factors for total mortality for men, women and all. Results of the analysis are presented by the hazard ratio (HR) by an increase of one unit and $95 \%$ confidence intervals (CIs)

\begin{tabular}{|c|c|c|c|}
\hline Risk factor & $\begin{array}{l}\text { Men }(n=439) H R^{\star} \\
(95 \% C I s)\end{array}$ & $\begin{array}{l}\text { Women }(n=563) H R \\
(95 \% \text { CIs })\end{array}$ & $\begin{array}{l}\text { All }(n=1003) H R \\
(95 \% \text { CIs })\end{array}$ \\
\hline \multicolumn{4}{|l|}{ Sociodemographic } \\
\hline Age at screening $(10 \mathrm{y})$ & $2.71(2.28,3.23)$ & $2.53(2.21,2.90)$ & $2.50(2.26,2.77)$ \\
\hline Household income (1-9) (1=lowest) & $0.91(0.82,1.00)$ & $0.96(0.88,1.03)$ & $0.95(0.89,1.01)$ \\
\hline Social security $(0=$ no, yes $=1)$ & $0.42(0.06,2.99)$ & $1.11(0.41,3.01)$ & $0.81(0.34,1.98)$ \\
\hline Married $(0=$ no, $1=$ yes $)$ & $0.69(0.41,1.15)$ & $1.06(0.71,1.57)$ & $1.15(0.86,1.54)$ \\
\hline \multicolumn{4}{|l|}{ Biological } \\
\hline Somatic illness ever $(0-3)(0=$ none $)$ & $1.17(0.95,1.46)$ & $1.06(0.89,1.27)$ & $1.08(0.94,1.24)$ \\
\hline Hospitalisation last year $(0=$ no, $1=$ yes $)$ & $1.09(0.56,2.11)$ & $1.49(0.87,2.57)$ & $1.34(0.88,2.04)$ \\
\hline Increased blood pressure $(0=$ no, $1=$ yes $)$ & $1.73(1.05,2.84)$ & $1.73(1.16,2.60)$ & $1.69(1.24,2.31)$ \\
\hline Angina pectoris $(0=$ no, $1=$ yes $)$ & $1.45(0.86,2.46)$ & $2.55(1.57,4.16)$ & $2.09(1.47,2.97)$ \\
\hline Myocardial infarction $(0=$ no, $1=$ yes $)$ & $2.32(1.26,4.24)$ & $2.44(1.23,4.83)$ & $2.60(1.66,4.06)$ \\
\hline Smoking $(0=$ no, $1=$ yes $)$ & $1.32(0.88,1.99)$ & $1.12(0.84,1.69)$ & $1.30(0.98,1.73)$ \\
\hline Sport $(1-5)(1=$ highest $)$ & $1.15(0.95,1.39)$ & $1.31(1.03,1.65)$ & $1.19(1.03,1.31)$ \\
\hline Outdoor exercise (1-4) (1=highest) & $1.13(0.95,1.35)$ & $1.30(1.10,1.54)$ & $1.16(1.03,1.31)$ \\
\hline \multicolumn{4}{|l|}{ 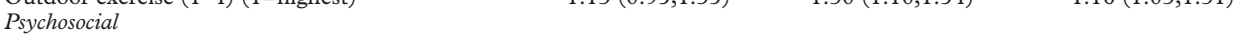 } \\
\hline Own assessement of health (1-4) (1=best) & $1.46(1.03,2.05)$ & $1.42(1.10,1.83)$ & $1.40(1.15,1.71)$ \\
\hline Relationship family $(0-5)(0=$ best $)$ & $1.08(0.94,1.25)$ & $0.99(0.88,1.12)$ & $1.01(0.92,1.11)$ \\
\hline Relationship friends (1-3) (1=best) & $0.86(0.69,1.08)$ & $0.90(0.74,1.10)$ & $0.90(0.78,1.05)$ \\
\hline Relationship neighbour (1-3) (1=best) & $1.03(0.93,1.14)$ & $0.93(0.83,1.04)$ & $0.96(0.89,1.04)$ \\
\hline Close relationship (1-9) & $0.93(0.86,1.00)$ & $0.99(0.92,1.06)$ & $0.95(0.91,1.00)$ \\
\hline Rotter's scale $(0-12)$ (low=internal) & $1.12(1.02,1.23)$ & $1.030 .95,1.13)$ & $1.04(0.98,1.11)$ \\
\hline Religious engagement $(1-3)(1=$ low $)$ & $0.93(0.61,1.42)$ & $1.01(0.78,1.31)$ & $0.90(0.73,1.12)$ \\
\hline Social participation $(1-3)$ (1=low) & $0.71(0.53,0.85)$ & $0.80(0.65,0.99)$ & $0.80(0.69,0.93)$ \\
\hline Frequency of interpersonal contact $(0-3)$ & $1.03(0.77,1.38)$ & $0.92(0.69,1.21)$ & $0.93(0.76,1.14)$ \\
\hline Mental health $(1-4)(1=$ worst $)$ & $0.85(0.72,1.00)$ & $0.86(0.74,0.99)$ & $0.88(0.79,0.97)$ \\
\hline $\operatorname{Depression}(0=$ no, $1=$ yes $)$ & $1.41(0.88,2.26)$ & $1.21(0.84,1.75)$ & $1.14(0.93,1.40)$ \\
\hline
\end{tabular}

${ }^{\star} \mathrm{HR}$ of cases per 1000 person years.

on mortality, even though low household income was almost significantly related to increased mortality.

Increased blood pressure, angina pectoris (women only), myocardial infarction, no sport and/or outdoor exercise (women only) were the biological factors predicting total mortality.

The sex differences, however, are probably not true, although the Cox analyses show estimates to differ numerically. The confidence intervals are overlapping, and statistical analyses by the $Z$ test on difference in the regression coefficients shows that there is a non-signicant difference between the sexes for these factors. In addition, we cannot see a plausible biological reason for a sex difference regarding the predictivity of these factors on total mortality.

It was surprising that smoking had no effect. However, when stratifying on cause of death, smoking turned out as a risk factor for cancer in age adjusted analyses. When analysing the data further, an association between being a previous smoker and having a history of cardiovascular disorder was detected. In other words, people who had suffered cardiovascular symptoms or disorder had tended to stop smoking, hence reducing the effect of smoking on mortality in our model. When adjusting for angina, myocardial infarction, and high blood pressure, in addition to age, smoking turned out to be a risk factor for total mortality and cancer.

Own assessment of health, lack of social participation, being "external" on Rotter's scale (men only), and having poor mental health (women only) were the psychosocial risk factors having a significant effect on mortality. Relatively few close relationships had a marginal significant effect.

To estimate the predictive effect of psychosocial variables on mortality, when controlling for the effect of biological and sociodemographic variables, adjusted proportional hazards regression analysis of single psychosocial risk factors was carried out. In this analysis only those psychosocial variables that showed a significant effect in the age adjusted analysis were included. Mortality was split into total mortality, cardiovascular disease, cancer, and "other causes" (table 4).

One or more causes of mortality were predicted by social participation, Rotter's scale, and the number of close relationships, whereas

Table 4 Adjustedt proportional hazards regression analysis of single psychosocial risk factors for mortality of men and women presented by the hazard ratio (HR) by an increase of one unit and 95\% confidence intervals (CIs)

\begin{tabular}{|c|c|c|c|c|c|c|c|c|}
\hline \multirow[b]{2}{*}{ Risk factor } & \multicolumn{2}{|c|}{ Total mortality } & \multicolumn{2}{|c|}{ Cardiovascular diseases } & \multicolumn{2}{|l|}{ Cancer } & \multicolumn{2}{|c|}{ Other causes of mortality } \\
\hline & men & women & men & women & men & women & men & women \\
\hline \multirow[t]{2}{*}{ Rotter's scale (0-12) } & $1.13^{\star}$ & 1.00 & 1.10 & 0.97 & 1.06 & 0.98 & $1.24^{\star}$ & 1.02 \\
\hline & $1.02,1.25$ & $0.91,1.09$ & $0.94,1.28$ & $0.85,1.10$ & $0.88,1.14$ & $0.80,1.20$ & $1.04,1.48$ & $0.84,1.18$ \\
\hline \multirow[t]{2}{*}{ Social participation (1-3) } & $0.65^{\star}$ & $0.80^{\star}$ & $0.63^{\star}$ & 0.85 & $0.38^{\star}$ & 0.93 & 0.99 & 0.65 \\
\hline & $0.50,0.84$ & $0.65,0.99$ & $0.43,0.92$ & $0.64,1.12$ & $0.23,0.64$ & $0.59,1.47$ & $0.60,1.61$ & $0.41,1.04$ \\
\hline \multirow[t]{2}{*}{ Close relationships (1-9) } & 0.93 & 1.02 & $0.82^{\star}$ & 1.07 & 1.08 & 1.00 & 0.93 & 0.95 \\
\hline & $0.86,1.01$ & $0.95,1.10$ & $0.71,0.95$ & $0.97,1.17$ & $0.94,1.25$ & $0.85,1.18$ & $0.80,1.08$ & $0.81,1.11$ \\
\hline \multirow[t]{2}{*}{ Mental health (1-4) } & 0.91 & 0.97 & 0.83 & 0.96 & 0.87 & 1.11 & 0.98 & 0.88 \\
\hline & $0.76,1.09$ & $0.82,1.15$ & $0.63,1.10$ & $0.77,1.20$ & $0.61,1.24$ & $0.78,1.58$ & $0.70,1.38$ & $0.60,1.28$ \\
\hline \multirow[t]{2}{*}{ Own assessment of health (1-4) } & 1.30 & 1.23 & 1.62 & 1.23 & 1.65 & 1.04 & 0.65 & 1.67 \\
\hline & $0.90,1.87$ & $0.92,1.64$ & $0.93,2.82$ & $0.85,1.84$ & $0.82,3.35$ & $0.53,2.04$ & $0.26,1.60$ & $0.96,2.89$ \\
\hline
\end{tabular}

tAdjusted for the following sociodemographic and biological risk factors: age at screening, household income, somatic illness ever, hospitalisation last year, increased blood pressure, angina, myocardial infarct,smoking, sport, outdoor exercise. ${ }^{\star} \mathrm{p}<0.05$. 
Table 5 Adjusted multivariate proportional hazards regression analysis of psychosocial risk factors for mortality of men and women presented by the hazard ratio (HR) by an increase of one unit and 95\% confidence intervals (CIs)

\begin{tabular}{|c|c|c|c|c|c|c|c|c|}
\hline \multirow[b]{2}{*}{ Risk factor } & \multicolumn{2}{|c|}{ Total mortality } & \multicolumn{2}{|c|}{ Cardiovascular diseases } & \multicolumn{2}{|l|}{ Cancer } & \multicolumn{2}{|c|}{ Other causes of mortality } \\
\hline & men & women & men & women & men & women & men & women \\
\hline \multirow[t]{2}{*}{ Rotter's scale (0-12) } & 1.08 & 0.96 & 1.06 & 0.96 & 0.98 & 0.96 & $1.25^{\star}$ & 0.93 \\
\hline & $0.98,1.20$ & $0.87,1.07$ & $0.90,1.24$ & $0.83,1.10$ & $0.81,1.18$ & $0.78,1.19$ & $1.05,1.50$ & $0.75,1.16$ \\
\hline \multirow[t]{2}{*}{ Social participation (1-3) } & $0.69^{\star}$ & $0.77^{\star}$ & 0.74 & 0.81 & $0.39^{\star}$ & 0.91 & 1.09 & $0.59^{\star}$ \\
\hline & $0.54,0.89$ & $0.61,0.96$ & $0.49,1.10$ & $0.60,1.08$ & $0.23,0.66$ & $0.56,1.46$ & $0.65,1.82$ & $0.36,0.99$ \\
\hline \multirow[t]{2}{*}{ Close relationships (1-9) } & 0.95 & 1.02 & $0.86^{\star}$ & 1.07 & 1.09 & 0.98 & 0.93 & 0.95 \\
\hline & $0.88,1.03$ & $0.95,1.10$ & $0.74,0.99$ & $0.97,1.18$ & $0.94,1.27$ & $0.83,1.17$ & $0.80,1.08$ & $0.80,1.13$ \\
\hline \multirow[t]{2}{*}{ Mental health (1-4) } & 0.94 & 1.00 & 0.86 & 0.96 & 0.93 & 1.14 & 1.01 & 0.97 \\
\hline & $0.78,1.14$ & $0.84,1.20$ & $0.63,1.16$ & $0.76,1.22$ & $0.63,1.36$ & $0.77,1.68$ & $0.71,1.43$ & $0.65,1.44$ \\
\hline \multirow[t]{2}{*}{ Own assessment of health (1-4) } & 1.17 & 1.28 & 1.37 & 1.23 & 1.65 & 1.16 & 0.56 & 1.87 \\
\hline & $0.80,1.70$ & $0.94,1.74$ & $0.79,2.40$ & $0.81,1.88$ & $0.77,3.55$ & $0.56,2.40$ & $0.22,1.42$ & $1.04,3.37$ \\
\hline
\end{tabular}

tAdjusted for the following sociodemographic and biological risk factors: age at screening, household income, somatic illness ever, hospitalisation last year, increased blood pressure, angina, myocardial infarct, smoking, sport, outdoor exercise. ${ }^{\star} \mathrm{p}<0.05$.

mental health and own assessment of health had no significant effect.

To look into the effect of each of these psychosocial predictors separately, when controlling for the others as well as the sociodemographic and biological variables, multivariate analysis was carried out (table 5).

Social participation seemed to be the strongest psychosocial predictor, affecting total mortality (men and women), cancer (men), and "other causes" (women). Rotter's scale predicted "other causes" among men, whereas number of close relationships predicted CVD among men. Mental health and own assessment of health did not predict mortality in this analysis.

\section{Discussion}

As expected, a number of factors related to cardiovascular disorder, like high blood pressure, angina pectoris, and myocardial infarction, increased mortality. Also as expected, physical excersise predicted mortality. Somewhat suprisingly, smoking was not significantly related to total mortality in the overall sample. This, however, could be explained by previous smokers having tended to stop smoking after having suffered cardiovascular symptoms or disorder, hence reducing the predictive effect of smoking in the study population. Smoking specifically predicted mortality of cancer in the age adjusted analysis.

With respect to the psychosocial variables included in the study, some predicted mortality, others did not. It is interesting that social participation turned out to be the most powerful predictor of mortality, whereas social support, in terms of number of close relationships, only showed an effect with respect to death of cardiovascular disorder in men. Quality of relationships to family, friends, and neighbours showed no effect. This relatively weak effect of social support compared with social participation is different from the findings in at least two other major studies, where the effect of the two types of predictors seemed rather equal. ${ }^{15}$ However, in general there are certain inconsistencies in the research findings in this field, probably related to differences in the network measures used.

When comparing the prediction of mortality with the prediction of mental health in the same study population, based on a 10 year follow up, some interesting differences were observed. Whereas social participation did not seem to be that important for mental health, social support and locus of control showed a predictive effect, but then only in interaction with negative life events. External locus of control in combination with poor social support increased the risk of developing mental disorder when exposed to negative life events. By themselves, neither poor social support nor external locus of control predicted mental health problems. As this seems to be the case with respect to mortality, at least for certain causes of death among men, this may indicate that the direct effect is more important for somatic health than mental health. The extent to which an interaction effect with negative life event is present for mortality, is however not possible to test in this study, as there is no information about negative life events for the last period preceding death.

Why social participation should have a strong direct effect on mortality, and social support only to a lesser degree, is an interesting question. However, it is probable that social participation is more related to inner, psychological resources and life style, having a rather stable effect on the control over one's own life, and thereby health; whereas the effect of social support is mainly related to the support provided by others during stressful life situations. This may be particularly so in this study, where the measure of social participation includes the feeling of being able to influence decisions taken in the groups. This would also be in line with the finding that internal locus of control, which to a great extent is supposed to reflect stable personality characteristics, seems to have a direct, positive effect on survival in this study. However, it is not easy to distinguish between the effect of inner psychological resources and outer social setting, as the two sets of variables tend to be closely related.

In discussing the findings of this study, it has to be kept in mind that even if the psychosocial variables predict mortality when controlling for various biological variables, the possibility cannot be ruled out that some of these still act as explanatory variables. The possibility exists that people low in social participation and social support develop a less healthy life style than the rest during the follow up period, with smoking and lack of physical exercise. It also has to be remembered that all the biological variables in the study are based on subjective 
assessment and self report, and that objective measures might modify the picture.

Lastly it must be emphasised that important factors related to life style as well as social relations are not included in the study, like excessive drinking, risk taking behaviour, coping style, and hostility. This means that these factors must be kept in mind as possible confounders when considering the findings of this study.

1 Berkman LF, Syme SL. Social networks, host resistance, and mortality: A nine-year follow-up study of Alameda County residents. Am F Epidemiol 1979;109:186-204.

2 House JS, Robbins C, Metzner HL. The association of social relationships and activities with mortality: Prospective evidence from the Tecumseh Community Health Study. Am f Epidemiol 1982;116:123-40.

3 Welin L, Tibblin G, Svärdsudd K, et al. Prospective study of social influences on mortality. Lancet $1985 ; \mathrm{i}: 915-18$.

4 Orth-Gomèr K, Undèn A-L, Edwards M-E. Social isolation and mortality in ischemic heart disease: A ten-year and mortality in ischemic heart disease: A ten-year follow-up study of 150 midd

5 Hanson BS, Isacsson S-O, Janzon L, et al. Social network and social support influence mortality in elderly men. - The prospective population study of "Men born in 1914", Malmö, Sweden. Am $\mathcal{F}$ Epidemiol 1989;130:100-11.

6 Kaplan GA, Wilson TW, Cohen RD, et al. Social functioning and overall mortality: prospective evidence from the Kuopio Ischemic Heart Disease Risk Factor Study. Epidemiology 1994;5:495-500.

7 Ruberman W, Weinblatt E, Goldberg JD, et al. Psychosocial influences on mortality after myocardial infarction. $N$ Engl 7 Med 1984;311:552-39.

8 Wiklund I, Odèn A, Sanna H, et al. Prognostic importance of somatic and psychosocial variables after a first myocardial infarction. Am ₹ Epidemiol 1988;128:786-95.

9 Östergren P-O. Psychosocial resources and health. With special reference to social network, social support and cardiovascular disease. Malmö: Lund University, Department of Community Health Sciences, 1991.

10 Syme L. Control and health: a personal perspective. In: Steptoe A, Appels A, eds. Stress, personal control and health. Chichester: John Wiley, 1989:3-18.

11 Cohen S, Wills TA. Stress, social support and the buffering hypothesis. Psychol Bull 1985;98:310-57.

12 Kessler CK, McLeod JD. Social support and mental health in community samples. In: Cohen S, Syme L,eds. Social support and health. New York: Academic Press, 1985:219-38.

13 Cassel J. The contribution of the social environment to host resistance. Am f Epidemiol 1976;104:107-23.

14 Brown GW, Andrews B, Harris T, et al. Social Support, self esteem and depression. Psychol Med 1986;16:813-31.

15 Cox T. Psychobiological factors in stress amd health. In: Fisher S, Reason J, eds. Handbook of life stress, cognition and health. Chichester: John Wiley, 1988:603-23.

16 Antonovski A. Health, stress and coping. San Francisco: Jossey-Bass, 1979.

17 Karasek RA, Theorell T. Healthy work: stress, productivity and reconstruction of working life. New York, NY: Basic Books, 1990

18 House JS. Work, stress and social support. Reading, MA: Addison-Wesley, 1981

19 Hanson BS, Östergren P-O. Social networks and health: theories and empirical evidence from Malmö, Sweden. Malmø: Lund University, Department of Community Health Sciences, 1994

20 Nowack KM, Sassenrath JM. Coronary-prone behavior, locus of control and anxiety. Psychol Rep 1980;47:359-64.

21 Williams RB, Poon LW, Burdette LJ. Locus of control and vasomotor response to sensory processing. Psychosom Med 1977;39:127-33.

22 Dalgard OS. Living conditions, social network and mental health. In: Isacsson S-O, Janzon L, eds. Social support health and disease. Stockholm: Almquist and Wiksell, 1986: 71-86.

23 Dalgard OS, Bjørk S, Tambs K. Social support, negative life events and mental health - a longitudinal study. $\mathrm{Br} f$ Psychiatry 1995;166:29-34.

24 Dalgard OS. Bomiljø og psykisk helse. Oslo: Universitetsforlaget, 1980.

25 Leighton AH, Leighton DC, Danly RA. Validity in mental health surveys. Can $\mathcal{F}$ Psychiatry 1966;3:167-78. 